\title{
What's in YOUR denominator?
}

Dawn S. Hui, MD, and Richard Lee, MD, MBA

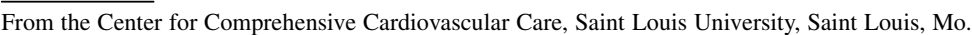 \\ Disclosures: Authors have nothing to disclose with regard to commercial support. \\ Received for publication Jan 5, 2017; accepted for publication Jan 12, 2017; available ahead of print Feb 24, 2017. \\ Address for reprints: Richard Lee, MD, MBA, Center for Comprehensive Cardiovascular Care, Saint Louis Uni- \\ versity, 3635 Vista Ave, DT 13F, St Louis, MO 63110 (E-mail: rlee@ slu.edu). \\ J Thorac Cardiovasc Surg 2017;154:147-8 \\ $0022-5223 / \$ 36.00$ \\ Copyright (C) 2017 Published by Elsevier Inc. on behalf of The American Association for Thoracic Surgery \\ http://dx.doi.org/10.1016/j.jtcvs.2017.01.009
}

In this issue of the Journal, Ad and colleagues ${ }^{1}$ describe their single-center experience with pacemaker implantation (PMI) following the surgical Cox-Maze procedure. The authors state that the study was prompted by the rate of PMI recently reported in the Cardiothoracic Surgical Trials Network (CTSN) trial, ${ }^{2}$ with a desire to study the "potential implication on the decision-making associated with surgical ablation of atrial fibrillation (AF)." They postulate that surgical technique is a major factor in the differing rates of PMI, identifying surgeon training and experience as an opportunity for improvement. However, a look at the data-theirs as well as others-suggests that there is more to the story.

In their multivariable analysis, a concomitant operation involving 2 or more valves was the only significant risk factor. Accordingly, a comparison of the rates of PMI across trials should take into account the heterogeneity of the study populations. A notably greater proportion of patients in both the CTSN and Atricure Bipolar Radiofrequency Ablation of Permanent Atrial Fibrillation (ABLATE) trials underwent a multiple valve operation (Table 1 ). In addition, a full $21 \%$ of the patients in the study by Ad and colleagues ${ }^{1}$ underwent isolated AF surgery, compared with all-concomitant operations in CTSN and ABLATE. Although length of stay is discussed in the paper as a tool to navigate the issue of PMI timing, the impact of heterogeneous patient characteristics and operations on length of stay across studies is a

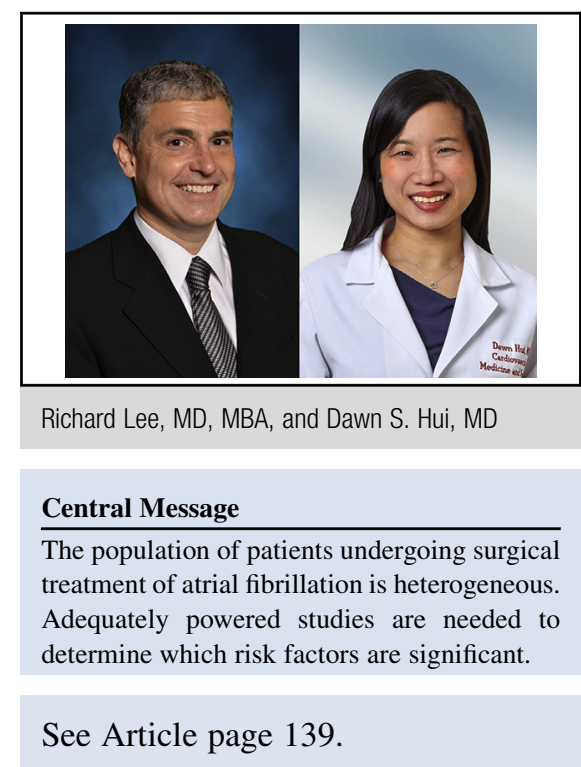

confounding factor. Further muddying the comparison, a number of additional factors have been reported inconsistently across studies, including the incidence of preoperative pacemaker, perioperative antiarrhythmic drug usage, and surgical technique such as the management of the cavo-tricuspid isthmus line. The use of perioperative antiarrhythmic drugs is of particular relevance to the return of sinoatrial node dysfunction, which is the predominant indication for PPM after Cox-Maze procedures.

Ad and colleagues are not the first to examine the rate of PMI after surgical ablation, and previous papers not referenced in their manuscript are worth briefly mentioning for further context. A much earlier experience found a trend towards increasing age in patients with early PMI. ${ }^{4}$ The authors of a more recent multivariate analysis found age

TABLE 1. Selective comparison of characteristics from recent surgical ablation studies

\begin{tabular}{|c|c|c|c|c|}
\hline & Ad and colleagues ${ }^{1}$ & CTSN, $^{2}$ ablation* & $\mathrm{CTSN}^{2}$ biatrial arm & ABLATE ${ }^{3}$ \\
\hline Age, $y$, mean $\pm S D$ & $63.4 \pm 11.1$ & $69.7 \pm 10.4$ & $68.2 \pm 10.4$ & $70.5 \pm 9.3$ \\
\hline Concomitant cardiac operation, $\%$ & 79 & 100 & 100 & 100 \\
\hline Multiple valve operation, $\%$ & 16.9 & 48.1 & 45.5 & 25.5 \\
\hline Nonparoxysmal AF, \% & NR & 100 & 100 & 92.7 \\
\hline PMI, \% & 7.0 & 19.5 & 24 & 22.9 \\
\hline \multicolumn{5}{|l|}{ PMI Indication } \\
\hline $\mathrm{SND}, \%$ & 67 & 35 & NR & 64 \\
\hline AVND, $\%$ & 23 & 54 & & 36 \\
\hline Intact conduction at late follow-up & $23 \%(12 / 52)$ & NR & NR & $54.5 \%(6 / 11)$ \\
\hline
\end{tabular}

CTSN, Cardiothoracic Surgical Trials Network; ABLATE, Atricure Bipolar Radiofrequency Ablation of Permanent Atrial Fibrillation; SD, standard deviation; AF, atrial fibrillation; $N R$, not reported; $P M I$, pacemaker implantation; $S N D$, sinus node dysfunction; $A V N D$, atrioventricular node dysfunction. *Includes the cohort randomized to PVI or biatrial maze. 
to be the only significant variable associated with both early and late PMI. Early rates of PMI were greater in those patient undergoing concomitant operations. ${ }^{5}$ The authors noted that those undergoing concomitant operations were on average a decade older than patients with lone CoxMaze. Similarly, more than half of the patients in the CTSN trial undergoing ablation were $>70$ years old. Whether age and multiple valve operations merely covary or are independent risk factors for PMI will require studies that are powered to answer this question. Ad and colleagues do not report the age range of their population, but it was notably younger than other studies, including by nearly a decade compared with ABLATE. With a similar standard deviation value, this raises the possibility of a truly significant different population.

Thus, a number of issues brought forth by this study raise the bar for examination of PMI rates after surgical ablation. We find it concerning, however, that the authors reference only one other study for PMI rate comparison and so strongly emphasize the role of surgical technique without clear context to support their assertion, especially given the disparate results with other expert AF centers such as Northwestern ${ }^{6}$ and Washington University. ${ }^{5}$ Given the disparity between the patient characteristics of their study and others, and considering the relationship between $\mathrm{AF}$ and valvular disease, 2 other possibilities exist: either patients undergoing AF surgery at their center are a different population than at other centers, or the management of valvular disease at this center is less aggressive than at other centers. Without a more homogeneous comparison, the deduction that surgeon training and experience should be the targeted area of opportunity is premature.

\section{References}

1. Ad N, Holmes SD, Ali R, Pritchard G, Lamont D. A single center's experience with pacemaker implantation after the Cox Maze procedure for atrial fibrillation. J Thorac Cardiovasc Surg. 2017;154:139-46.

2. Gillinov AM, Gelijns AC, Parides MK, DeRose JJ Jr, Moskowitz AJ, Voisine P, et al. Surgical ablation of atrial fibrillation during mitral-valve surgery. $N$ Engl J Med. 2015;372:1399-409.

3. Philpott JM, Zemlin CW, Cox JL, Stirling M, Mack M, Hooker RL, et al. The ABLATE trial: safety and efficacy of Cox maze-IV using a bipolar radiofrequency ablation system. Ann Thorac Surg. 2015;100:1541-6.

4. Worku B, Pak S, Cheema F, Russo M, Housman B, Van Patten D, et al. Incidence and predictors of pacemaker placement after surgical ablation for atrial fibrillation. Ann Thorac Surg. 2011;92:2085-90.

5. Robertson JO, Cuculich PS, Saint LL, Schuessler RB, Moon MR, Lawton J, et al. Predictors and risk of pacemaker implantation after the Cox-maze IV procedure. Ann Thorac Surg. 2013;95:2015-21.

6. Churyla A, Iddriss A, Andrei A, Kruse J, Malaisrie C, Passman R, et al. Biatrial or left atrial lesion set for ablation during mitral surgery: risks and benefits. Ann Thorac Surg. 2017;103(6):1858-65. 